\title{
A Simple Timing Shutter for Stimulus-Presentation Devices ${ }^{1}$
}

WILLIAM BUCHANAN and ROBERT FRANK WEISS, UNIVERSITY OF OKLAHOMA, Norman, Oklahoma 73069

Transparent mirror glass can be used to construct inexpensive and highly reliable timing shutters for stimulus-presentation systems. $A$ representative circuit and $a$ simple stimulus-display device using $3 \times 5$ index cards are also described.

The use of transparent mirror glass (popularly miscalled "one-way glass") in room-sized installations is well known. This material, consisting of ordinary glass with a transparent but highly reflective coating, can also be used to construct nonmechanical timing shutters for use with stimulus-presentation devices.

For his studies of attitude conditioning through persuasive communications, Weiss (1968) required precise $( \pm .005 \mathrm{sec})$ measurement of response time to a series of brief statements. The transparent mirror timing shutter was developed to replace a succession of solenoid-operated mechanical systems (e.g., Weiss, Rawson, \& Pasamanick, 1963). It consists of a pane of transparent mirror glass, through which $S$ views the stimulus items, with lights mounted on both sides of the pane. The lights on S's side of the pane make the glass reflective and therefore opaque to $S$; those on the E's side render the glass transparent, showing the stimulus materials. Since the operation of the shutter is solely dependent on the electrical switch that alternates the lights, a timer (or any other electrical device) can be synchronized precisely with the shutter operation.

Figure 1 shows one of the units now in use. The $7 \times 3$ in. pane is mounted at a slight angle to the vertical in a partition between a control room and a subject room. Two pairs of $71 / 2-\mathrm{W}, 125-\mathrm{V}$ lamps are used. The control room "on" lights have clear bulbs and are mounted directly above the glass. The subject-room "off" lights have colored bulbs and flank the pane. A baffle of thin sheet metal is mounted below the pane such that, in the "off" mode, it is reflected by the pane, rendering it opaque.

Figure 2 shows a representative control

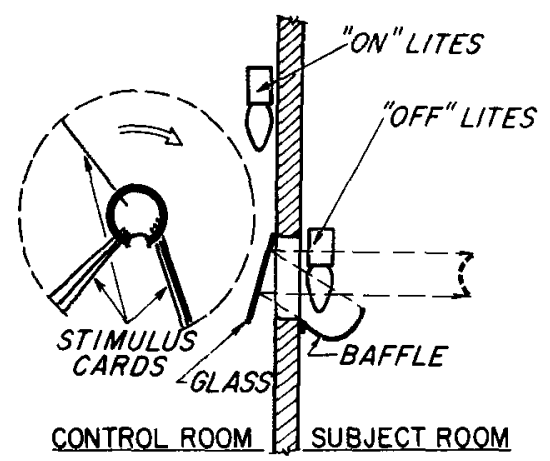

Fig. 1. Typical installation of shutter and stimulus-presentation device in partition or panel separating $E$ from $S$.

circuit for the system, using a clutch-actuated readout timer to measure latency of response. $\mathrm{E}$ initiates the trial with a pushbutton (S1) that energizes a 3PDT relay. The relay remains selfenergized (by R1A) until S responds (with $\mathrm{S} 2$ ) or $\mathrm{E}$ terminates the trial (with S3, which also resets the timer). The timer

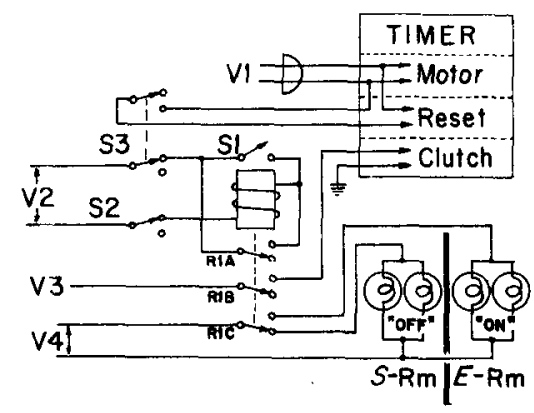

Fig. 2. Circuit for timing stimulus-onset/S-response interval. The transparent mirror glass is Libby-Owens-Ford "Mirropane." The electrical components are as follows: R1-Potter \& Brumfield KL 17A relay, $115 \mathrm{~V}$ ac, 4 PDT; Standard S1 timer, $.01 \mathrm{sec}, 125 . \mathrm{V}$ dc clutch; GE lamps, $115 \mathrm{~V}$, $7 \frac{1}{2} \mathrm{~W}$, candelabra base; S1-switch, SPST toggle; S2-switch, SPDT pushbutton; S3-switch, DPDT phone-switch. The power supply is a built-up, fused $125-\mathrm{V}$ $\mathrm{ac} / \mathrm{dc}$ unit constructed from salvaged components. and shutter lights operate simultaneously through R1B and R1C. Each component of the system-timer motor, clutch, controls, and shutter lights-can be operated on an independent circuit (V1-4).

The stimulus-display unit for the apparatus consists of the ring binder from a pocket notebook, placed as shown in Fig. 1 on mounting fashioned from scrap. Stimulus items are typed or printed on $3 \times 5$ index cards that have been punched to fit the binder. $\mathrm{E}$ flips each card into viewing position during the "off" mode. In practice, this operation is no more difficult than operating switches.

While the initial construction of the unit is quite simple, careful adjustment of the lamps and baffle are required to obtain satisfactory operation. If this is not done, the glass may remain dimly transparent when "off" or retain distracting residual reflections when "on." In the present installation, this adjustment was obtained without shielding the units and with normal room illumination.

The system described is simple, flexible, and satisfactory where a less than fully automatic system is acceptable and where precisely timed interpresentation intervals are not required. Its major advantages are low initial cost (under $\$ 10$, exclusive of timer), speed, and low cost of preparing new test materials, and, above all, reliability-the two units now in service have each operated for at least 10,000 cycles without malfunction. With large numbers of $S s$ to be run in a variety of studies, these factors far outweigh any advantages of such semiautomatic devices as slide projectors and memory drums.

\section{REFERENCES}

WEISS, R. F. An extension of Hullian learning theory to persuasive communication. In A. G. Greenwald, T. Brock, and T. Ostrom (Eds.), Psychological foundations of attitudes. New York: Academic Press, 1968. Pp. 109-145. WEISS, R. F., RAWSON, H. E., \& PASAMANICK, B. Argument strength, delay of argument, and anxiety in the "conditioning" and "selective learning" of attitudes. Journal of Abnormal \& Social Psychology, 1963, 67, 157-165.

\section{NoTE}

1. This research was supported in part by Grant MH-12402 from the National Institute of Mental Health. 